\title{
The Study of Flexural Capacity of Cross Section of Carbon Fiber Reinforced Plastic High Toughness Cementitious Composites
}

\author{
Gu-Jian HUANG \\ CCCC Second Highway Consultants Co., Ltd., Wuhan, Hubei,430056,China \\ huanggujian@163.com
}

\begin{abstract}
Keywords: Carbon Fiber Reinforced Plastic (CFRP) High Toughness Cementitious Composites, Flexural Capacity of Cross Section, Calculation Theory, Our-point Bending Test.
\end{abstract}

\begin{abstract}
According to the constitutive relation built based on the uniaxial tensile and compression tests of ECC, we proposed the calculation theory of flexural capacity of cross section of CFRP-ECC based on plain cross-section assumption. According to the result of four-point bending test, we proved the validity of calculation theory by comparing and analyzing the result of calculation theory and test. The comparison show that result of the calculation theory of flexural capacity of cross section and test agrees well, and the maximum error is under $4 \%$. This research result can provide reference for the structural calculation of non-metallic reinforced high toughness cementitious composites.
\end{abstract}

\section{Introduction}

How to increase the deformation and improve the brittleness of concrete, and these problems has caused the attention of the scholars both at home and abroad. Engineered Cementitious Composites ${ }^{[1-3]}$, which is a short fiber reinforced cement based on fracture mechanics, microscopic physical mechanics and statistical optimization design. The fiber volume is not more than $2.5 \%$ of the total volume, and has strain hardening and fracture characteristics under tensile load. The stable tensile strain can reach above 3\%, and material specimen shows that the maximum crack width can be controlled within 100 microns .Due to the material toughness and good durability can solve the above problems, both at home and abroad have been applied in practical engineering, such as the Hong Kong-Zhuhai-Macao bridge in our country and Japan yokohama, building, etc.

Traditional reinforced concrete structures are easily to cause the loss of bearing capacity and eventually led to the problem of poor durability, because cracking in the process of use within the vulnerable to environmental impact and corrosion of reinforcement. In order to solve this problem, experts and scholars try using high-performance materials instead of steel so as to improve the structure durability. $\mathrm{CFRP}^{[4]}$ is a high performance carbon fiber composite material composed of carbon fiber and matrix .It has light weight, high strength, corrosion resistance, fatigue resistance and other advantages. It is better to solve the problem of the durability of steel caused by corrosion instead of steel in concrete members.

There is significant difference between reinforced concrete and CFRP-ECC materials in constitutive relation and ordinary reinforced concrete normal section flexural analysis theory is not applicable. Based on ECC uniaxial tensile and compressive constitutive relation, and combination of CFRP tensile stress-strain relationship, we put forward the normal section flexural bearing capacity calculation theory suitable for CFRP-ECC structure. At the same time, from the four-point bending test of CFRP-ECC specimen, we are trying to prove the correctness of the computational theory through the comparison and analysis. 


\section{The Analysis Theory of Flexural Capacity of Cross Section}

\section{The Constitutive Relation of ECC}

Based on the obtained experimental data of uniaxial tension and compression experiments of ECC specimens, fitting the stress-strain curve and the constitutive relations are as follows:

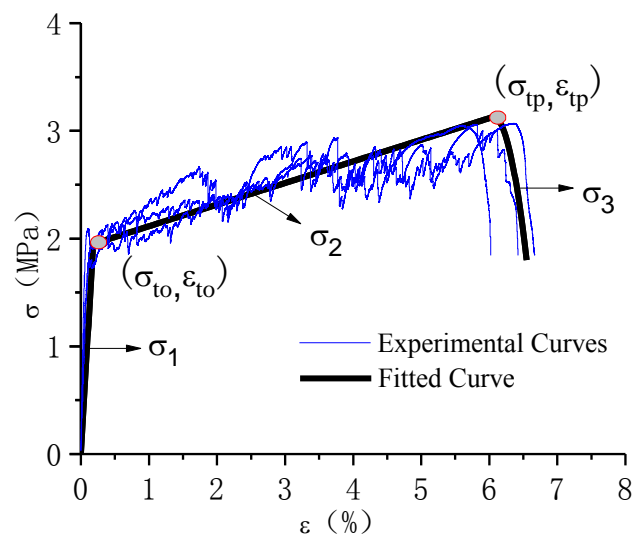

(a) Tensile Model

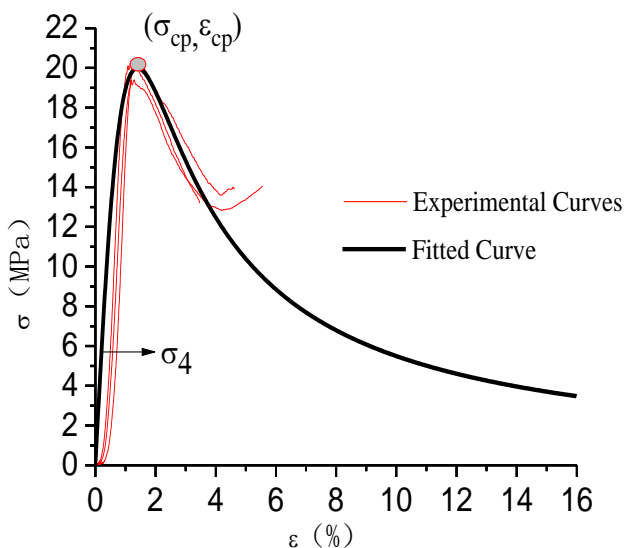

(b) Compression Model

Fig.1 The Constitutive Relation of ECC

Tensile constitutive relation:

$$
\left\{\begin{array}{l}
\sigma_{1}=\sigma_{t 0}\left(\frac{\varepsilon}{\varepsilon_{t 0}}\right)^{\alpha_{e}}, 0 \leq \varepsilon<\varepsilon_{t 0} \\
\sigma_{2}=\sigma_{t 0}+\frac{\varepsilon-\varepsilon_{t 0}}{\varepsilon_{t p}-\varepsilon_{t 0}}\left(\sigma_{t p}-\sigma_{t 0}\right), \varepsilon_{t 0} \leq \varepsilon<\varepsilon_{t p} \\
\sigma_{3}=\sigma_{t p}+\left(\sigma_{t u}-\sigma_{t p}\right)\left[3\left(\frac{\varepsilon-\varepsilon_{t p}}{\varepsilon_{t u}-\varepsilon_{t p}}\right)^{2}-2\left(\frac{\varepsilon-\varepsilon_{t p}}{\varepsilon_{t u}-\varepsilon_{t p}}\right)^{3}\right], \varepsilon_{t p} \leq \varepsilon<\varepsilon_{t u}
\end{array}\right.
$$

Of which: $\varepsilon_{t 0}=0.0018, \varepsilon_{t p}=0.0606$ are respectively crack tensile strain and ultimate tensile strain; $\sigma_{t 0}=1.95 \mathrm{MPa}, \sigma_{t p}=3.13 \mathrm{MPa}$ are respectively crack tensile stress and ultimate tensile stress.

Compress constitution relationship:

$$
\sigma_{4}=\sigma_{c p} \cdot \frac{n \cdot\left(\varepsilon / \varepsilon_{c p}\right)}{1+(\mathrm{n}-2) \cdot\left(\varepsilon / \varepsilon_{c p}\right)+\left(\varepsilon / \varepsilon_{c p}\right)^{2}}, \varepsilon<0, n>0
$$

Of which: $\varepsilon_{c p}=0.014$ is the ultimate compressive strain; $\sigma_{c p}=20 \mathrm{MPa}$ is the ultimate compressive stress, and $n=2$.

\section{Normal Section Flexural Bearing Capacity Calculation Theory}

CFRP reinforced materials have no yield stage. Its reasonable damage shall take the break of ECC at the compressive zone as the judgment, and the CFRP reinforcement material has yet to reach the ultimate tensile strength, so the specimens should be designed to the reinforcement. Along with the increase of the cross section of tensile stress of the lower edge, the bending CFRP reinforcement should be at the elastic stage of the whole process. ECC has the characteristics of tensile strain hardening, so the tensile stress of lower limb must be considered when calculating the bearing 
capacity of normal section flexural member. On the basis of the above ideas, the CFRP-ECC normal section bending process can be divided into three stages:
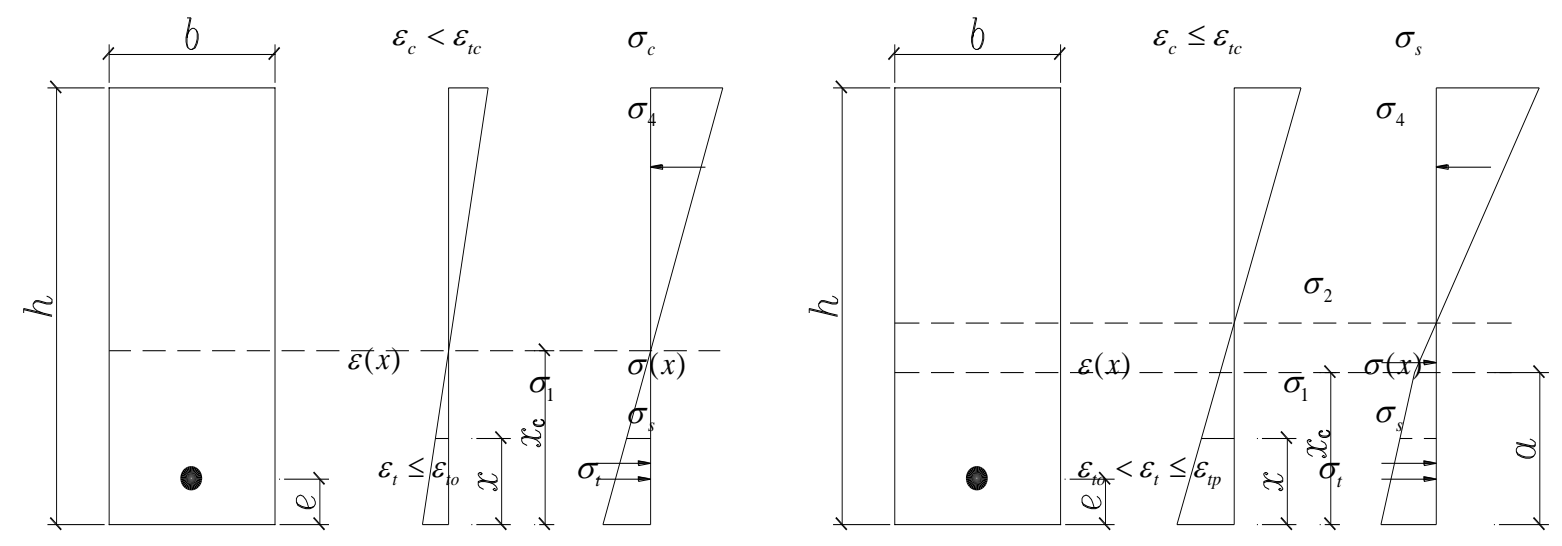

Linear in Tensile and Compressive Zone (b) Linear in Compressive Zone and Bilinear in Tensile Zone

Fig.2 Distributions of Stress and Strain along the Depth at Different Stages

Of which: $\sigma_{s}, A_{s}, E_{s}$ are respectively the section stress, cross section area and elastic modulus of CFRP reinforcement materials, $a$ is the distance from the turning point of the tensile stress to the bottom of the cross section of tensile zone, $e$ is the distance between the center of reinforcement material and the bottom of the cross section of tensile zone, $x_{c}$ is the depth of neutral axis.

From the flat section assumption, when we take $\varepsilon_{t}$ which is the bottom of the ECC tensile strain as independent variable, we can get the strain at any point on cross section:

$$
\varepsilon(x)=\varepsilon_{t} \cdot\left(1-x / x_{c}\right), 0 \leq x \leq h
$$

Elastic stage (linear in tensile and compressive zone $\varepsilon_{t} \leq \varepsilon_{t o}, \varepsilon_{c}<\varepsilon_{c p}$ );

The section internal force equilibrium equations at the elastic stage:

$$
\left\{\begin{array}{l}
\sum N=\int_{0}^{x_{c}} b \cdot \sigma_{1}(\mathrm{x}) d x-\int_{x_{C}}^{h} b \cdot \sigma_{4}(\mathrm{x}) d x+\sigma_{S} \cdot A_{S}=0 \\
\sum M=\int_{x_{C}}^{h} b \cdot \sigma_{4}(\mathrm{x}) x d x-\int_{0}^{x_{C}} b \cdot \sigma_{1}(\mathrm{x}) x d x-\sigma_{S} \cdot A_{S} \cdot e=M
\end{array}\right.
$$

Elastic-plastic stage (linear in compressive zone and bilinear in tensile zone $\left.\varepsilon_{t o}<\varepsilon_{t} \leq \varepsilon_{t p}, \varepsilon_{c} \leq \varepsilon_{c p}\right)$;

The section internal force equilibrium equations at elastoplastic stage:

$$
\left\{\begin{array}{l}
\sum N=\int_{0}^{a} b \cdot \sigma_{2}(\mathrm{x}) d x+\int_{a}^{x_{c}} b \cdot \sigma_{1}(\mathrm{x}) d x-\int_{x_{c}}^{h} b \cdot \sigma_{4}(\mathrm{x}) d x+\sigma_{S} \cdot A_{S}=0 \\
\sum M=\int_{x_{c}}^{h} b \cdot \sigma_{4}(\mathrm{x}) x d x-\int_{0}^{a} b \cdot \sigma_{2}(\mathrm{x}) x d x-\int_{a}^{x_{c}} b \cdot \sigma_{1}(\mathrm{x}) x d x-\sigma_{S} \cdot A_{S} \cdot e=M
\end{array}\right.
$$

Failure stage (There is no formula at this stage, and ECC damage at pressure zone and components lose bearing capacity for $\varepsilon_{c}>\varepsilon_{c p}$ ). 


\section{Four-point Bending Test}

\section{The Preparation of Test Pieces of CFRP-ECC}

The main material of CFRP - ECC are CFRP tendons, PVA fiber, fine sand, fly ash, water, ordinary Portland cement, water reducing agent. The label of cement is 42.5; Secondary fly ash, 45 micron square hole sieve margin from $12 \%$ to $25 \%$; Water reducing agent choose poly carboxylic acid high performance water reducing agent (produced by the second shipping harbor in Wuhan new material co., LTD.,); Sand is standard sand, getting through the sieve analysis experiment, particle size control in about 200 microns; Test water use bottled drinking water, in line with the "The water standard of concrete mixing water ".

CFRP, commonly known as carbon fiber reinforced plastic, which is one of the commonly used reinforcement material of structure, and compared with ordinary steel materials, which has high strength, small density, good durability, nonmagnetic, environmental protection, etc. CFRP tendons` stress strain curve has a linear relationship under tensile load, and material won't appear plastic performance before destruction. Its performance indicators such as table 1:

Tab.1 Properties of CFRP

\begin{tabular}{ccccccc}
\hline Material & $\begin{array}{c}\text { Ultimate } \\
\text { elongation } \\
(\%)\end{array}$ & $\begin{array}{c}\text { Stress } \\
\text { relaxation } \\
\left(20^{\circ} \mathrm{C}\right)(\%)\end{array}$ & $\begin{array}{c}\text { Elasticity } \\
\text { modulus } \\
(\mathrm{GPa})\end{array}$ & $\begin{array}{c}\text { Density } \\
\left(\mathrm{kg} / \mathrm{m}^{3}\right)\end{array}$ & $\begin{array}{c}\text { Tensile } \\
\text { strength } \\
(\mathrm{MPa})\end{array}$ & $\begin{array}{c}\text { Ultimate tensile } \\
\text { strain }(\%)\end{array}$ \\
\hline CFRP & $0.5 \sim 1.7$ & $1 \sim 3$ & 170 & 1750 & 1870 & 1.1 \\
\hline
\end{tabular}

ECC refers to a kind of high toughness composite material that has strain hardening characteristics and more seam cracking performance, consisting of PVA fiber, cement, sand, fly ash and so on.PVA performance indicators such as table 2:

Tab.2 Properties of PVA Fiber

\begin{tabular}{ccccccc}
\hline Material & $\begin{array}{c}\text { Length } \\
(\mathrm{mm})\end{array}$ & $\begin{array}{c}\text { Diameter } \\
(\mu \mathrm{m})\end{array}$ & $\begin{array}{c}\text { Tensile elastic } \\
\text { modulus }(\mathrm{GPa})\end{array}$ & $\begin{array}{c}\text { Density } \\
\left(\mathrm{g} / \mathrm{cm}^{3}\right)\end{array}$ & $\begin{array}{c}\text { Tensile strength } \\
(\mathrm{MPa})\end{array}$ & $\begin{array}{c}\text { Elongation } \\
(\%)\end{array}$ \\
\hline PVA & 12 & 39 & 43 & 1.3 & 1620 & 7.0 \\
\hline
\end{tabular}

\section{The Experimental Loading Method}

This experiment adopts two symmetrical loading methods, and then carries on the four-point bending test.

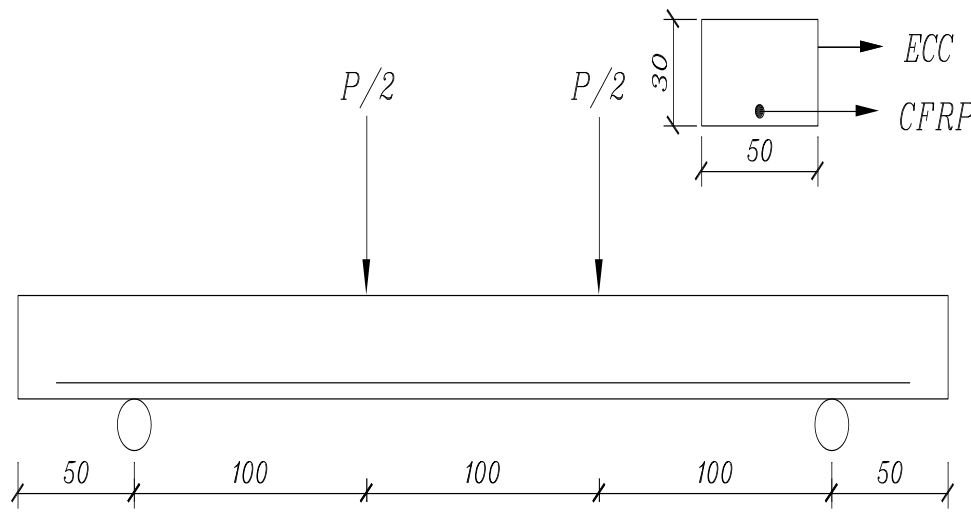

Fig.3 The Sketch Map of Test Load and Specimen Section 


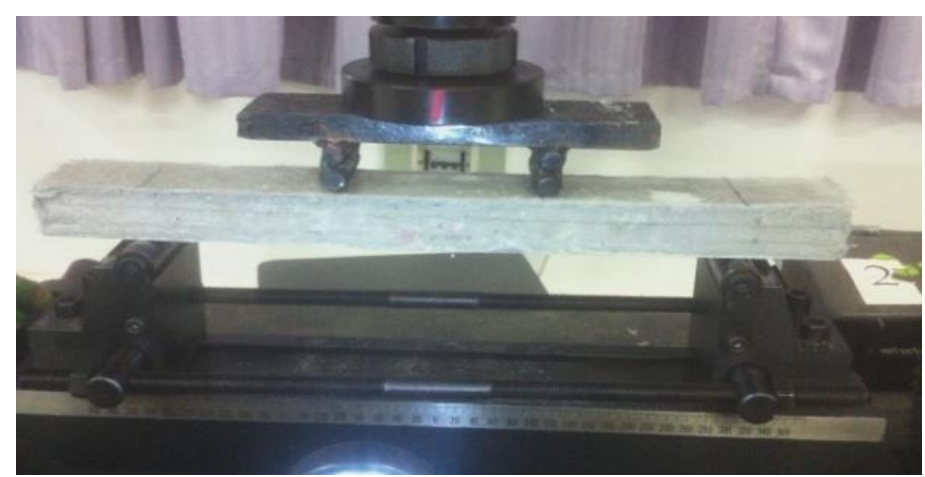

(a) The Early Loading

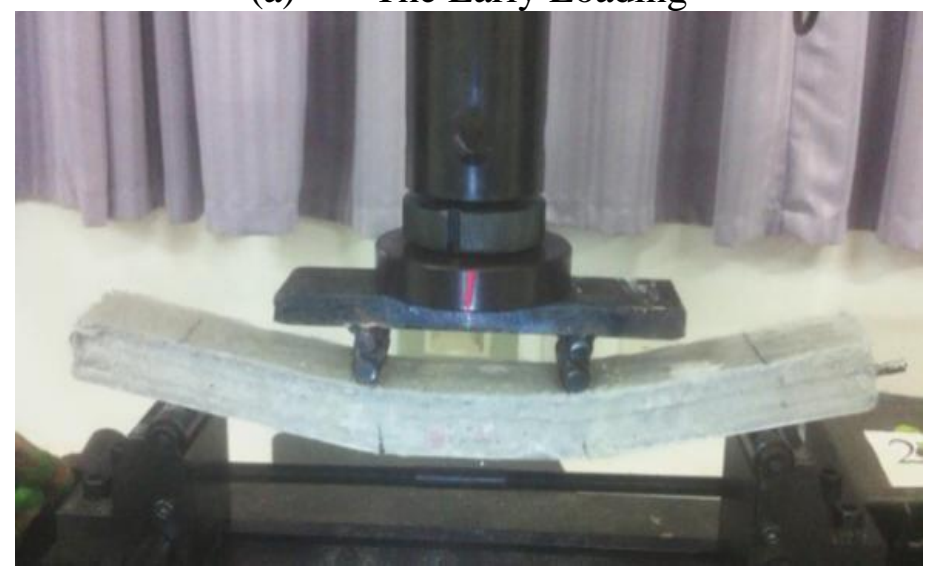

(b) Loading to Damage

Fig.4 The Map of Test Load

\section{The Theoretical Calculation Results Compared with the Experimental Results}

The size of test specimen is $30 \mathrm{~mm} \times 50 \mathrm{~mm} \times 400 \mathrm{~mm}$, so $h=30 \mathrm{~mm}, b=50 \mathrm{~mm}$. The loading part length $l=300 \mathrm{~mm}$; the distance from the center of CFRP reinforced material to the bottom of tensile zone of $\mathrm{ECC} e=8 \mathrm{~mm}$.

Theoretical Calculation. According to the formula (1), (2), (3), (4), we can deduce the formula (6) at elastic stage:

$$
\frac{b \cdot x_{c} \cdot \sigma_{t 0}}{2}-b \cdot x_{c} \cdot \sigma_{c p} \cdot \frac{\varepsilon_{c p}}{\varepsilon_{t}} \cdot \ln \left(1+\left[\left(h-x_{c}\right) \varepsilon_{t} /\left(x_{c} \cdot \varepsilon_{c p}\right)\right]^{2}\right)+\frac{x_{c}-e}{x_{c}} \cdot \varepsilon_{t} \cdot E_{s} \cdot A_{S}=0
$$

We let $\varepsilon_{t}=\varepsilon_{t o}$, and the lower edge of test specimen which reaches cracking tensile strain is cracking at this time. The neutral axis height $x_{c}=11.95 \mathrm{~mm}$, cracking moment $M_{c r}=25.47 \mathrm{~N} \cdot M$, cracking load $P_{c r}=6 M / l=509.47 \mathrm{~N}$.

According to the formula (1), (2), (3), (5), we can deduce the formula (7) at elastic-plastic stage:

$$
\begin{aligned}
& a \cdot b \cdot \sigma_{t 0}+\frac{b \cdot\left(\sigma_{t p}-\sigma_{t o}\right)}{\varepsilon_{t p}-\varepsilon_{t o}} \cdot\left[\frac{\left(2 \cdot a \cdot x_{c}-a^{2}\right) \cdot \varepsilon_{c}}{2 \cdot\left(h-x_{c}\right)}-a \cdot \varepsilon_{t o}\right]+\frac{b \cdot \sigma_{t o} \cdot \varepsilon_{c}}{\varepsilon_{t o} \cdot\left(h-x_{c}\right)} \cdot\left[x_{c}\left(x_{c}-a\right)-\frac{\left(x_{c}-a^{2}\right)}{2}\right]+ \\
& b \cdot \sigma_{c p}(h-c) \ln 2+\frac{x_{c}-e}{x_{c}} \cdot \varepsilon_{t} \cdot E_{s} \cdot A_{S}=0
\end{aligned}
$$

We let $\varepsilon_{c}=\varepsilon_{c p}$, and the upper edge of test specimen which reaches ultimate compress strain is about to destroy. The neutral axis height $x_{c}=13.21 \mathrm{~mm}$, ultimate bending moment $M_{u}=144.20 \mathrm{~N} \cdot M$, ultimate load $P_{u}=6 M / l=2883.86 \mathrm{~N}$. 
At this time, CFRP`s $\sigma_{s}=E_{s} \cdot \varepsilon_{s}=E_{s} \cdot\left(x_{c}-a\right) /\left(h-x_{c}\right)=580 M P a<1870 M P a$, so CFRP is still at plastic stage.

Experimental Result. We can get the corresponding initial crack load and ultimate load of three specimens through the load time curve obtained by loading test, and drawn the initial crack and ultimate load theoretical values in figure 5, from which we can know that it is close to the test value.

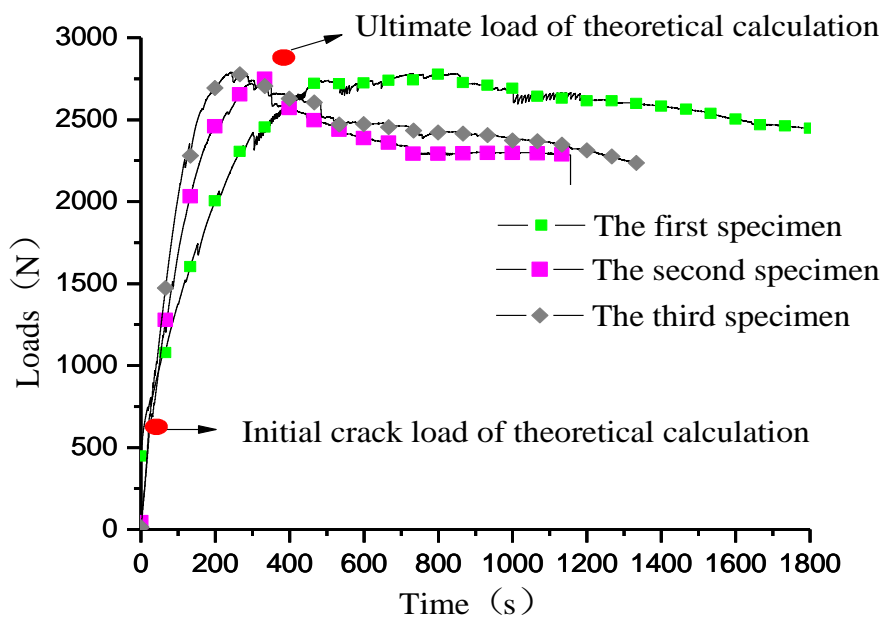

Fig.5 The Curve of Test Load and Time

Error Analysis. The test values and theoretical values of three specimens and the error analysis listed in the table 3 below:

Tab.3 The Error Analysis Table

\begin{tabular}{ccccccccc}
\hline \multirow{2}{*}{ Load types } & \multicolumn{3}{c}{ Test value(N) } & \multirow{2}{*}{ Theoretical } & \multicolumn{3}{c}{ Error(\%) } & Maximum \\
\cline { 2 - 3 } values(N) & 1 & 2 & 3 & & 1 & 2 & 3 & error (\%) \\
\hline $\begin{array}{c}\text { Initial } \\
\text { cracking load }\end{array}$ & 528 & 520 & 514 & 509.47 & 3.55 & 2.09 & 1.01 & 3.55 \\
Ultimate load & 2779 & 2788 & 2781 & 2883.86 & 3.76 & 3.42 & 3.69 & 3.76 \\
\hline
\end{tabular}

By the above analysis result, the maximum error of the theoretical calculated values and experimental values of the initial cracking load is $3.55 \%$, and the maximum error of the theoretical calculated values and experimental values of ultimate load is $3.76 \%$, and all are less than $4 \%$. Proving that the calculation values is very close to the experimental values, and proved the correctness of the normal section flexural bearing capacity calculation theory based on the flat section assumes of the CFRP reinforcement of high toughness composites (CFRP - ECC) in this paper.

\section{Conclusions}

On the basis of the flat section assumption, the calculated values obtained by theoretical calculation method proposed for CFRP-ECC are in good agreement with those obtained in experimental value, and the error is not more than $4 \%$, which prove that the proposed calculation theory is correct.

For ECC has the performance of tensile strain hardening, in this paper, we considered the contribution of tensile ability of the lower edge of ECC to the bearing capacity, which occupies $16 \%$ and $20 \%$ of the total tension through the calculation, so the tensile of ECC is not negligible when calculating the CFRP-ECC's flexural bearing capacity of normal section. We choose CFRP as the reinforced material because of its capacity of normal section. We choose CFRP as the reinforced material because of its high strength, small density, good durability, nonmagnetic, environmental advantages, so it is one of the composite material which can be promoted. 
Our research results can provide a reference for the calculation and analysis of the non-metal and high toughness reinforced material.

\section{References}

[1] Li V C. Advances in ECC research [J]. ACI Special Publication on Concrete: Material Science to Applications, 2002: 373-400.

[2] Zhang J, Li V C, Andrzej S N, Wang S. Introducing ductile strip for durability enhancement of concrete slabs [J]. Journal of Materials in Civil Engineering, 2002, 14(3):253-261.

[3] Li V C, Leung C K Y. Steady state and multiple cracking of short random fiber composites [J]. Journal of Engineering Mechanics, ASCE, 1992, 188(11):2246-2264.

[4] P. J. Hefferman, M. A. Erki. Fatigue Behavior of Reinforced Concrete Beams Strengthened with Carbon Fiber Reinforced Plastic Laminates [J]. J. Compos. Constr, 2004, 4(3), 132-140.

[5] Balaguru, P, Contribution of fibers to crack reduction of cement composites during the initial and final setting period, 1994. (3), 180-288. 